\title{
Revuelta popular en Venezuela
}

Manuel Shutherland

Sólo arriesgando
la vida, conserva uno la libertad. Hegel

Resumo: Uma das insurreições mais contundentes na América nos últimos 50 anos, o "Caracazo" motivou debates e ações que levaram ao fim do bipartidarismo venezuelano. O evento ensejou golpes de Estado e aplainou o caminho para a democracia chavista e as pautas do "progressismo" do século XXI. Expressamos alguns aspectos que buscam romper com certa mitologia populista que envolve o 27 de fevereiro de 1989.

Palavras-chave: Insurreição; Populismo; Venezuela.

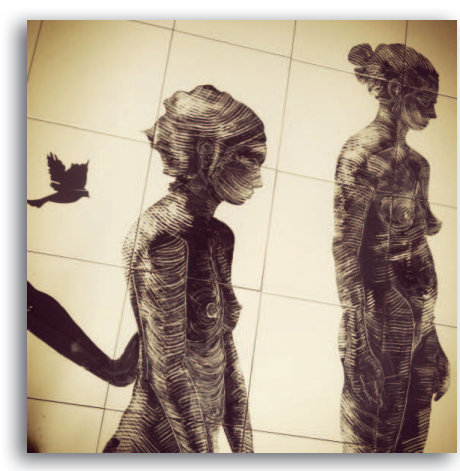

\section{Popular rebellion in Venezuela}

Abstract: One of the most striking upheavals in America in the last 50 years, the "Caracazo" motivated discussions and actions that led to the end of bipartisanship in Venezuela. The event provided an opportunity for coups and paved the way for Chavezstyle democracy and the guidelines of "progressivism" of the XXI century. We express some aspects that try to break with some populist mythology surrounding February 27, 1989.

Keywords: Uprising; Populism; Venezuela.

\section{Manuel Shutherland}

Coordenador de Investigações. Associação LatinoAmericana de Economia Política Marxista. 


\section{CRÓNICA DE LA REVERSIÓN DEL “PARAÍSO” DE LA ACUMULACIÓN RENTISTA}

Venezuela está catalogada hoy como primera reserva mundial de petróleo; la "fertilidad" de sus pozos y la facilidad de extracción permitieron que tras duras luchas se nacionalizase precariamente la explotación de hidrocarburos y el país viviera épocas donde la burguesía y las capas medias pudieron hacer del derroche la suntuosidad y la chocarrería su leitmotiv. Los años de recuperación del capitalismo 60-70 y hasta la depresión mundial del 71-74 le dieron al país cierta estabilidad bajo las democracias asesinas devenidas del Pacto de Punto Fijo, firmado en octubre de 1958. Se cuentan por miles el número de desaparecidos de la lucha que sostuvo el Punto Fijismo contra la izquierda nacional, con especial énfasis contra el Partido Comunista, quien en mayoría se fue a la lucha armada, y sufrió el extraño fenómeno de la subida del ejército a las montañas y la masacre de casi todos los guerrilleros.

Las crisis energéticas y la construcción de la OPEP le dieron a Venezuela la posibilidad de captar rentas diferenciales de gran magnitud, que se tradujeron en bonanza efímera y una especie de pacto social donde, a pesar de haber mucha pobreza, había capas medias muy gastadoras que drenaban la renta en importaciones suntuosas, mediante monedas sobrevaluadas y un gasto público asistencialista y populachero. Es sabido que la marca de Champaña Crystal de Moet Chandon (de las más caras del mundo), de Francia, reportó que la Discoteca Paladium, en Caracas, fue el local que más vendió su producto fuera de Francia, de hecho invitaron a los dueños del local a un paseo por la Ciudad de las Luces. En Venezuela había vuelos diarios a Miami, donde el venezolano compraba compulsivamente, y era famoso por la frase: "Está barato, dame dos".

El "consumismo" (que el chavismo achaca a toda la población sin distingo de clases sociales) fue una cultura proveniente de esas épocas, donde la sobrevaluación fue una manera efectiva de drenar los dólares, que el portento rentístico le regaló a la burguesía y sus servidores directos. La sobrevaluación aún se mantiene en el chavismo, el tipo de cambio (2009) reafirma la noción gastadora, que aunada a una inflación promedio anual de 30\% y tasas de 
interés reales negativas, incita a la gente a gastar, para protegerse de la pérdida de valor, de esa fetichizada mercancía dinero, que según Marx (1858) es el resumen de todas las relaciones sociales del sistema, almacenable en una cartera.

En los dorados años 1970 e inicios de los 1980, los venezolanos (de altos ingresos) eran muy conocidos en el mundo por sus millonarias compras y dineros tirados a la basura. Esa destrucción de la renta en lo más frívolo del consumo colaboró al estancamiento y lumpenización transversal de la sociedad, donde la lectura, la educación y la formación eran aplastadas por la puerilidad consumista. De allí, la estadounidización (EEUU) tan grande que subsiste en el país, y que sorprende a propios y extraños. Las formas de clientelismo político, la "compra" de cuadros políticos y la maraña de redes corruptelas en post de captar la renta hicieron de la burguesía venezolana una de las más atrasadas de América, la cual reconcentró en las finanzas y la importación sus principales negocios.

Así las cosas, los fallidos procesos de sustitución de importaciones - proyecto rescatado en la actualidad, como un desarrollismo de nuevo tipo - y de la defensa a la industria nacional, dieron lugar a los casos de corrupción más grotescos del país. Se podría afirmar con toda certeza que los créditos blandos y subsidios fueron entregas directas a la burguesía criolla en post de retiros dorados y fiestas suntuosas. El petróleo, que mató el agro criollo, en esa célebre decisión de Juan Vicente Gómez, de revaluar la moneda, hizo que actualmente la producción agropecuaria ni siquiera se mida como actividad en la cuenta del PIB. El escritor Zambrano (1989, p. 16) nos comenta con meridiana claridad que:

El peculado, que llega a magnitudes astronómicas, ha impedido el empleo de los gigantescos presupuestos en el mejoramiento de las condiciones de vida de los sectores populares [...] el sorprendente fortalecimiento de la oligarquía monopólica, en asociación con las transnacionales, ha profundizado la brecha entre una minoría opulenta y una mayoría cada vez más miserable y desvalida.

Ese "paraíso" sufrió un serio revés con la crisis de los 1980. Los aumentos en la tasa de interés, el excesivo endeudamiento (e incluso calificado por los más moderados como antipatriótico) y la baja de los precios de los hidrocarburos (por la contracción de la 
demanda mundial bajaron de 30 US\$ a 10 US\$ en el fatídico año 1983) revierten los "oasis" de la acumulación rentística y muestran de lleno la miseria e incapacidad de la burguesía nacional para llevar adelante las tareas de desarrollar las fuerzas productivas y mantener los niveles de crecimiento. La burguesía dio todo lo que pudo dar, bajo esas condiciones estructurales de la economía de un país excolonial, de escaso desarrollo tecnológico, de pequeño mercado y de baja escala productiva. Por ello, la estructura empresarial se muestra impotente para industrializar al país y generar la cantidad de empleos necesarios para ofrecer empleos de calidad a la mayoría de la población.

\section{DEUDA, EXTORSIÓN Y EMPOBRECIMIENTO DEL PUEBLO VENEZOLANO}

Los huecos fiscales empujaron a que, del año 1975 al 1980, la deuda externa creciera en casi 600\%, causando que Venezuela entrase en moratoria de pagos en los años 1983 y 1988. La tasa de interés estadounidense que en el año 1977 se ubicó alrededor del 5\%, subió para 1981 a un impagable 19\%, haciendo que de la receta del servicio de la deuda (interés + capital) ni siquiera el interés pudiera remunerarse y la deuda creciese en magnitudes faraónicas. Las políticas fuertemente contractivas de la administración Reagan destruyeron las posibilidades de pago en el país. Ah, pero, por si fuera poco, las corredoras de riesgo (ahora quebradas) consideraban muy peligrosa a la nación, aumentando el indicador Riesgo País, lo que obligaba a erogar más bolívares por préstamos con intereses más que astronómicos.

El servicio de la deuda en relación al PIB subió en América Latina (AL) del 14\% al 34\% en sólo dos años (1982-1984). En 1973 la deuda total de AL era de 137 mil millones de US\$, en 1979 ascendió a 390 billones de US\$ y ya para el año 1985 la deuda llegó a 860 mil millones de US\$ (TOUSSAINT, 2004).

El gobierno de Jaime Lusinchi en su quinquenio de 1985-1989 canceló 25 billones de US\$, el 93\% de ello fue sólo en intereses; al final de su período dejó a los venezolanos: 32 billones de verdes en deuda, es decir, de la fortuna pagada, casi toda se fue en intereses y casi nada en amortización. Famoso es el título en la Prensa donde el Presidente confiesa que la banca lo "engaño", que 
lo engatusaron, algo así como pecar de ingenuidad. Al parecer, el Presidente firmó un acuerdo "sin saber" y absorbió o nacionalizó buena parte de la deuda externa privada. De esa forma, protagonizó uno de los episodios más lamentablemente idiotas y nocivos para nación alguna. La socialización de las pérdidas de la burguesía llegó a extremos inimaginables.

Lo que constituye un mecanismo de exacción formidable - la deuda externa -, que aún actúa de manera infame en nuestros países; los gobiernos progresistas insisten en seguir reproduciendo con religiosidad y orgullo. Son famosas las notas que le añadían al pago de la deuda externa con el FMI, por parte del chavismo en el año 2007, el ministro de Finanzas Rodrigo Cabezas la denominó como: "La tercera independencia de Venezuela, un histórico acto de gallardía y soberanía". Aunque en el fatídico año 2009, el gobierno contrató 3.600 millones de US\$ con el FMI, en unos Derechos Especiales de Giro (DEG), que parecen echar por tierra el discurso "libertador" de pagar la deuda.

Así, burguesías más fuertes, de acumulación más sólida, emprendieron, bajo la terriblemente efectiva ideología neoliberal, un fantástico plan para la recuperación de la tasa de ganancia, que caía en picada. De esa forma, eliminaron a buena parte del capital "sobrante", arruinaron a los capitales menos productivos y relanzaron el proceso de acumulación capitalista. Todo ello se realizó con mecanismo de centralización y concentración de capital donde se proletarizó a millones y se empobreció a otros tantos. Los procesos de privatización, liquidación de empresas nacionales y el desarrollo de la destrucción de la legislación laboral se produjeron con el baño de sangre más grave de la Venezuela que recién (1975) nacionalizaba su renta. El 27F es el clímax de la opresión de la burguesía al pueblo pobre.

Es por demás interesante cómo la Academia Nacional de la Historia en Venezuela decidió rendir un homenaje de reconocimiento al ex presidente Jaime Lusinchi por todo lo que ha hecho a favor de la cultura y la historia de éste país. iYa sabemos cómo es el cerebro y como está el bolsillo de quienes nos cuentan la historia de nuestra América! Por ello, jamás sorprendió el Premio Nobel de la Paz a Obama, quien ha llenado de sangre el mundo, en aras de defender el sistema que llena de miseria a la humanidad. 


\section{DESARROLLO NACIONAL, EFECTO DE UNA QUIMERA}

La explosión de la crisis se tradujo en empobrecimientos brutales de la población ya en situación urbana de marginalidad, debido al caótico crecimiento citadino. De hecho, Barrios (1998, p. 13) nos cuenta que: "[...] el $90 \%$ de los barrios que albergan al $40 \%$ de la población se asientan en el 10\% del territorio de la ciudad". Y González (2005, p. 23) nos narra: "[...] en 1950, los barrios de Caracas albergaban a 117.000 habitantes, en 1981 dicha cifra se elevó a 1.440.000 personas". Por ello, ante la crisis, se experimentó un terrible deterioro de las condiciones de vida del obrero, que trató de crear un auge en la reproducción del capital, en base a salarios de miseria. El investigador Cueva $(2007$, p. 15) lo resume:

[...] el añorado desarrollo nacional autónomo no fue, en efecto, más que una quimera. La economía venezolana no logró desarrollar un mecanismo autónomo de acumulación, puesto que ésta siguió dependiendo en última instancia de la dinámica del sector petrolero exportador [...].

Lo que aunado a la entrada tardía en el sistema comercial mundial, el pequeño tamaño de mercado y demás trabas estructurales impedían el crecer de opciones no petroleras de sostenimiento nacional. La pobreza explotó y un proceso de indigentización estalló en las manos de los líderes de la nación.

El caos fue colosal. Las reservas operativas disminuyeron a casi 1.000 millones de dólares. La inflación llegó a 35\%, en 1988, cifra que no se corresponde con las duplicaciones de precios de bienes de la cesta básica, pero que fue la ofrecida por el inefable INE, que lleva años maquillando y corrompiendo la estadística. La tasa de interés real negativa y la fuga de divisas para el periodo (1982-1988) fueron - moderadamente - de 25 billones de dólares. Esto agravó la situación a un nivel de marginalización crónico. La burguesía nacional le indexó a la nación su deuda privada y además trató de mantener su "competitividad protegida" usando dólares preferenciales y diluyendo con devaluaciones sus deudas en bolívares.

De hecho, se creó el Sistema de Asignación de Divisas a precios preferenciales para empresarios "patriotas" que invertían y producían en el país. Ese mamotreto se llamó RECADI, y fue una de las instituciones donde la corrupción llegó a proporciones que 
dejarían el reinado de Luís XIV como un dechado de honestidad. La facilidad con que se conseguían dólares para su reventa y la falta de recursos técnicos para su control - lo que hechos querían -, hicieron actos de mágicas desapariciones de millones de US\$. Tremendo negocio. Sin embargo, la fiesta debía terminar de alguna forma.

Desde el 2005 existe CADIVI, un férreo control de cambio, que sólo permite comprar a los venezolanos con tarjetas de crédito, unos 2.500 US\$ al año para gastar en turismo, 400 US\$ para compras en internet y 500 US\$ para efectivo en caso de viajes. CADIVI, a pesar de vender todos los US\$ al mismo precio, funge para que los empresarios se enriquezcan de forma similar, inventando facturas, inventando deudas, importaciones, clonando tarjetas de crédito para obtener divisas y revenderlas en el mercado paralelo, donde las divisas se cotizan con un diferencial cambiario de 189\%. Tremendo negocio de nuestros burgueses que no paran de enriquecerse a manos llenas. iCómo hace falta socialismo revolucionario en nuestra América!

\section{4 “CON LOS ADECOS SE VIVE MEJOR, ROBAN PERO DEJAN ROBAR, CUANDO SE BAÑAN SALPICAN"}

El 18 de febrero de 1989 asume el presidente Carlos Andrés Pérez (CAP), quien había tenido un gobierno de fuerte carácter populista que gozó de ingresos ingentes que desarrollaron el clientelismo de manera exponencial. Un socialdemócrata, secretario de la Internacional Socialista y lleno de excentricidades como regalarle un barco a Bolivia y ser amigo de las causas por la libertad en el mundo, al amparar a gran cantidad de perseguidos políticos en el mundo.

Una campaña de televisión absolutamente divorciada de la realidad sembró la esperanza que rezaba: "con los adecos (partidarios del partido socialdemócrata Acción Democrática) se vive mejor, roban pero dejan robar, cuando se bañan salpican". Pero, como decía Hegel y luego completaba Marx (1915, p. 93) en el 18 Brumario: "Todos los grandes hechos y personajes de la historia universal aparecen, como si dijéramos, dos veces... una vez como tragedia y la otra como farsa", CAP de 1974 a 1979 por CAP 1989 
a 1994, así, apareció este Mesías del populismo que vino a enfriar la lucha de clases con un pequeño lanzallamas llamado Plan de Ajuste Macroeconómico Estructural.

Tal como Constantino I vio la cruz en el 312, una inscripción: "in hoc signo vinces" (con este símbolo vencerás), CAP imaginó a una cohorte ideal de planificadores del relanzamiento de la acumulación capitalista en base a salarios de miseria, teniendo a la devaluación de la moneda como buque insignia de una "sinceración económica" que traería beneficios que jamás llegaron. De la misma forma, se planteó la teoría del Shock (muy de Milton Friedman) y los aparatos ideológicos de la derecha (medios de comunicación) empezaron a irrigar la "urgente" necesidad de reajustar la economía, parar el derroche (gasto público para la educación, salud, cultura etc.), reducir el Estado y modernizar al país.

Aunque los burgueses no son ni keynesianos ni neoliberales, son capitalistas que buscan maximizar su beneficio o asegurar la tasa de ganancia más alta posible, así, cuando la situación lo requiere, utilizan políticas de ambas corrientes de manera indistinta; la balanza de pagos tenía un déficit de 4.390 millones de US\$ más las cartas de crédito negociadas con el FMI que rondaban los 7 billones de US\$. Había reservas operativas por sólo 1.500 millones de US\$ y un servicio de deuda que rozaba 6,1 billones. A CAP le tocaron las verdes y muy a su pesar las implementó a rajatabla, por encima de un charco de sangre que aún no se ha secado.

Su plan de seis años barrería con el capital chico, impulsaría la destrucción del capital más ineficiente, permitiría adquirir negocios a bajo precio, y lo más importante, sería un factor clave en el disciplinamiento de la clase obrera, con base en la deconstrucción de la seguridad laboral y el abaratamiento de la fuerza de trabajo. El gran capital contra el pequeño capital y la clase obrera.

Esta última determinación explica la animadversión a los monopolios y parte del endiosamiento al sector Pequeñas y Medianas Empresas (PYME) dentro del chavismo. Las PYME con su baja escala tecnológica suelen suplir su ineficiencia e ineficacia con plusvalía absoluta (extensión de la jornada de trabajo), desmejoras laborales - trabajos sin seguridad social - y empeoramiento de las condiciones de trabajo. El chavismo en su búsqueda del 
socialismo del siglo XXI no entiende que la lucha del pequeño capital es por el florecimiento de la propiedad privada que maneja, no el interés social.

Volviendo a 1989, el maravilloso trabajo de Martínez (2008, p. 28) comenta que el gobierno buscaba: "obtener préstamos por 4.500 millones de dólares en los siguientes tres años, el gobierno intensificó los compromisos con el FMI, anunciando, el 16 de febrero, la aplicación de un paquete macroeconómico." El "Paquetico Rodríguez" como se conoció dicho plan, diseñado por el economista Miguel Rodríguez (ex "marxista" progresista), fue un plan tan antiobrero que incluso "dulces amigos del pueblo" como Carl Popper, Raymond Aaron y Von Hayek lo habrían considerado demasiado drástico para el país. Pero como dice Sartelli (2004, p. 87) los pequeños patrones o capataces de la burguesía que vienen del proletariado suelen ser peores y más reaccionarios que a quienes defienden. En este caso fue exactamente así. La desproporción de las medidas es aún hoy célebre, por su inicua insensibilidad y su extremismo de tintes ridículos.

\section{5 ¿QUÉ PROPONÍA EL PLAN DE AJUSTE ESTRUCTURAL (PAE)?}

Siendo sucintos vemos de qué se trata el PAE:

$\checkmark$ Uniformidad en los tipos de cambio, es decir, devaluación de $150 \%$. Inflación de $80 \%$.

$\checkmark$ Solicitación de 4.500 millones de dólares ante el FMI, lo cual implicó la aceptación de su programa económico.

- Aumento anual de los productos derivados del petróleo durante tres años consecutivos.

ح Reducción del déficit fiscal eliminando gastos "innecesarios", subsidios, gasto social, protección a jubilados, etc.

$\checkmark$ Liberalización de los precios y aumento de los mismos en los servicios públicos. Aumentos de la gasolina, electricidad, teléfono, acero en: 110\%, 150\%, 40\% y 100\%, respectivamente.

$\checkmark$ Entrada al GATT, antigua OMC. Eliminación de trabas a la entrada de mercancías y de capitales al país. Reducción general de aranceles. 
$\checkmark$ Elevación general de los tipos de interés (se vieron tasas activas de hasta 40\%).

• Reducción del tamaño de Estado a su mínima expresión, es decir, privatizar lo máximo posible.

No falta ser un súper comunista para entender que el resultado de estas políticas depara en mayores miserias. En el estudio de Martínez se observa una alarmante distribución del ingreso: "Mientras la remuneración del trabajo (en salarios) era de 61,2\% en 1960 [la participación de la clase obrera en el Ingreso Nacional], de 50,4\% en 1970, de 27\% en 1980, a finales de los 1980 disminuyó hasta 15\%" (MARTÍNEZ, 2008, p. 94). El proceso de robo y enriquecimiento más rápido y salvaje en la historia del país. La burguesía comercial y financiera ganó, pero la industrial y agraria no.

La forma como le imputaron la crisis a la clase obrera fue descarada y la burguesía agraria e industrial vio como de un plumazo muchas de sus prebendas, protecciones y ventajas comerciales que les garantizaba su estado, para seguir produciendo de manera no competitiva, desaparecían en aras del "paquete". El ajuste iba a arruinar directamente a la burguesía dedicada a actividades relativas a manufacturas y a la burguesía más débil. Los iba a poner a disputarse mercados sin las "ayuditas" del Estado. Por ello, el ala más socialdemócrata y la de los pequeños capitales se opuso al Ajuste y a soto voce planeó un regreso o al menos un freno al "Paquetico Rodríguez" por una vía blanquista tropical (un golpe de Estado dirigido por una élite popular).

\section{CÓMO ERA EL AMBIENTE VIVIDO PREVIO A LA INSURRECCIÓN, SAQUEOS, CORTES DE RUTAS E INCENDIOS}

Las medidas del paquete, como es costumbre, contrarias a lo prometido, anunciadas a nueve días de una victoriosa jornada electoral, donde el bipartidismo obtuvo cerca del $90 \%$ de los votos y en la cual la izquierda fue comparsa, venían de grandes derrotas, sobre todo por el fracaso estrepitoso de la lucha armada, iniciada en los años 1960, que selló un divorció del comunismo con las masas y llevó a la muerte a más de 2.000 cuadros del Partido Comunista de Venezuela (protagonista de la lucha armada) y cargó a otros miles de combatientes 
(venidos de fracciones del PCV o de partidos menores) a la cárcel y al exilio (las cifras exactas de esas muertes aún son un misterio).

Todo ello, sin contar con el increíble viraje de la intelectualidad "crítica" proveniente de las universidades, que de tanto descalabro apelmazado, no vio otra forma de vivir que aprovechar sus saberes para hacerse de los puestos vacantes de la intelectualidad orgánica del capital.

Esta derrota le abrió las puertas al oportunismo para un decisivo salto que marcó el grave atraso en centros de pensamiento crítico como la Universidad Central de Venezuela (UCV). Los otrora marxistas y luchadores sociales ucevistas son ahora las brigadas de choque de la ultraderecha en su intención de sumergir al país más allá de la ruina.

\section{CLAMOR POPULAR POR LA TAN ANHELADA JUSTICIA SOCIAL}

Por esos días se generaron ciertas provocaciones, que atizaron el clamor popular de justicia social. Al ganar las elecciones, CAP, con un 53\% de la votación generalmente amañada, con su frase predilecta "acta mata votos", el gobierno recién elegido aunque predicó desde el inicio la austeridad, se lanzó al ruedo presidencial con una ceremonia de coronación, caracterizada por el derroche y bacanales pantagruélicos con mayor pompa que el de muchos emperadores romanos. Los aumentos de precio, el acaparamiento y la especulación para tratar de crear descontento ante el advenimiento de las medidas FMI, causaron un malestar realmente importante, la fastuosidad de la investidura. ${ }^{1}$

Según el Informe Económico de Facultad de Ciencias Económicas y Sociales de la UCV, la pobreza se había más que duplicado en dez años, de hecho, en 1978 habían 2.750.000 pobres absolutos, cifra que en 1988 llegó a 6.625.000, dígito que rozaba el $60 \%$ de la población. Pero ello se dio en un mar de enriquecimientos ilícitos de descaros inimaginables. Incluso, adecos como Gumersindo Rodríguez admitían públicamente que: "en la pasada administración (de Lusinchi, otro adeco) hubo grandes negociados que se hicieron a la sombra, el privilegio y la influencia

1 Varios artículos de prensa de la época reseñan el festín. 
gubernamental." ${ }^{2}$ Uno de esos mecanismos de riqueza fácil era la devaluación programada, para que la oligarquía hiciese de la compra y venta de divisas un deporte muy lucrativo. La devaluación entre el año 1984 y 1989 fue de 250\%.

\section{EL SECTOR ESTUDIANTIL TOMABA EN SUS MANOS LA VANGUARDIA DE LAS LUCHAS REIVINDICATIVAS}

El sector de mayor actividad referida a la protesta y agitación era sin duda el estudiantil. El retroceso político de la izquierda marxista y sus infinitos fraccionamientos dejaron en manos de los estudiantes universitarios el peso de llevar ciertas luchas reivindicativas. De hecho, el sector estudiantil tenía gran prestigio, no eran poca cosa las luchas protagonizadas por la Generación del 28 contra Gómez y en 1958 contra Pérez Jiménez. Ya, en 1989, el Movimiento 80 (M80), integrado por restos de la Juventud de la Liga Socialista y con el apoyo del rector Luis Fuenmayor, tuvo la oportunidad de motorizar una serie de protestas bastante violentas alrededor de la universidad; y tras sus capuchas, avanzar en la eficaz organización estudiantil a través de la Coordinadora Nacional de la FCU. Así, se pudieron coordinar insubordinaciones interesantes ante las medidas de CAP-FMI y su implantación forzosa.

Tras esa situación, latente estaba la protesta por la muerte de un estudiante llamado Dennis Montaño y de un empleado universitario Carlos Yépez, lo que representó un sólido basamento estudiantil de gran indignación, que llevó a realizar movilizaciones previas, enfrentaron toda clase de represiones y persecuciones. En las medidas del paquete también estaba el plan de privatización universitaria y se había hecho público que el aumento salarial de 30\% no iba a ser para los maestros. Tal como nos cuenta Rivas $(1999$, p. 1) la semana previa es la clave de la chispa que encendió la pradera:

La semana (20-24/02/89) caracterizada por violentos disturbios estudiantiles a escala nacional, CAP anuncia el incremento en el precio de la gasolina, efectivo el 24-25/02/89. El sábado 25/02/89 en reunión la dirigencia estudiantil [...] planifica movilizaciones para el lunes 27/02/89. Durante esas 48 horas, los

2 Entrevista de Alfredo Peña a Gumersindo Rodríguez, Diario El Nacional, fecha 19/2/89. 
estudiantes prepararon una nueva jornada de disturbios violentos [...] una jornada de protesta más.

La PM se preparó para enfrentarse contra los encapuchados en las adyacencias de la UCV, como una rutina más. De hecho, muchas veces habían ido los esbirros del ayer, a dispararle balas de plomo (no los balines de plástico, usados ahora), en la UCV y otras universidades del país hay decenas de monolitos a los caídos en batallas estudiantiles contra la policía. Varios de esos policías - incluido el nefasto grupo de la muerte Zeta, ahora son gobierno - Todo este ambiente era visto con cierta simpatía por muchos de la fracción adeca y por víctimas burguesas de las medidas, que ya tenían días azuzando al país, con acaparamiento, especulación y desaparición de alimentos. Una especie de lockout patronal que invitaba a la gente a la protesta llevada por el hastío.

Al escribir la historia de los hechos del 27 de febrero de 1989, también debe recordarse la importante lucha de los caficultores en el Estado Lara. Ellos sostuvieron enfrentamientos con oficiales del ejército y policía en una heroica toma del edificio del Ministerio de Agricultura y Cría, en la Avenida de los Abogados. Toda esa valerosa protesta entre el 30 de enero al 20 de febrero fue un estímulo importante a la población a salir a las calles, y a que algunos vieran posibilidades de sedición a la vista.

El 27 de febrero en Caracas, los transportistas convocan a Paro, por la casi duplicación de la gasolina que los "conducía" a descargar el peso del aumento, en el pasaje interurbano e intra-urbano, lo cual el gobierno no quería reconocer al aceptar un aumento muy pequeño en las tarifas. Así, los chóferes, organizados en "solidarias" cooperativas, decidieron aumentar el pasaje de Caracas a la Guaira de 10 Bs. a 15 Bs. y de Guarenas a Caracas de 10,5 Bs. a 20 Bs. Por ello, no es casualidad que los motines iniciales se realizarán en esas zonas y en el terminal de Caracas que las comunica: Nuevo Circo. Guarenas y Guatire quedan a más o menos 1 hora de la capital, desde allí se iniciaron los motines. Así, desde la 6 AM empezaron las quemas de cauchos, cierres de vías y una particular animadversión a los transportes que se manifestó en fotos que muestran la quema de una gran cantidad de los mismos. 


\section{DE PROTESTA A REVUELTA. FACTORES DE SEDICIÓN Y AGITACIÓN}

Ante todos los acontecimientos planteados con anterioridad, la burguesía no financiera, que en conchupancia (alianza deshonesta) con sus aliados que aún trabajaban en el Estado, jugó a atizar la sublevación y empleó técnicas de estímulo para darle mayor vigor a una posible sedición. Así, estos sectores percibiran la oportunidad de montarse en la ola desestabilizadora y respondieron con tácticas orientadas a la recuperación de la captación de su provento rentístico, captado por la vía de la sobrevaluación, subsidios y protecciones arancelarias.

El acto fue creciendo poco a poco y según el marxista:

[...] el país empieza a marchar a la ausencia del aparato político del gobierno, no hay políticas de contención organizadas y se genera una especie de vacío de poder [...] el gobierno sólo arranca la represión sistemática 24 horas luego [...] (DUNO, 1989, p. 31).

También nos comenta:

No hubo pancartas, ni convocatorias, no dirigió la Federación de Estudiantes, no hubo partidos que la organizaran, no hubo militares descontentos [...] sólo represión para la construcción de miles de expedientes amañados para construir un movimiento subversivo (expost) (ARIZMENDI, 1989, p. 62).

Así, el 27F tiene esa aura anarquista, en la cual se omiten detalles importantes que velan intereses que unos cuantos anhelaban.

\section{LA ACCIÓN DE POLICÍAS Y MOTORIZADOS DISIP Y DEL DIM COMO INSTIGADORES}

Sin analizar el contexto económico, pareciese una mera casualidad la aparición de motorizados pantaneros (policías motorizados vestidos de civiles) que según Rafael Rivas: "Aparecen de forma masiva y se incorporan a los disturbios". Dicha incorporación consistía en atizar a las masas, brindarle apoyo al saqueo con herramientas disímiles y facilitar la destrucción de locales.

O primero que nos comenta Ochoa (1989, p. 20, 28): "A los motorizados: pude verlos de un lado a otro de la ciudad, como veloces animales de metal, arengando al pueblo, provocando la insurrección, llevando y trayendo noticias de lo que estaba ocurriendo". 
Según Iturriza López (2009, p. 112): “Algunos son capaces de descubrir en los motorizados a los policías que organizaron a los saqueadores".

Vivas nos trae a la memoria que, "en ese momento, irrumpe un grupo de motorizados, lanzando consignas contra el gobierno de Pérez, a la par que un grupo de personas utilizando piedras y tubos arremeten contra la Santamaría de un negocio de víveres" (VIVAS, 2005, p. 1).

Los saqueos no surgieron de la nada, las armas cortas que los policías entregaron, los palos y tubos para saquear no fueron un regalo cándido de los uniformados, no. Eso equivaldría a decir que los policías se hicieron rebeldes o, incluso, revolucionarios en unas horas y que luego se les pasó la emoción y regresaron a su rutina represora. Estos policías, que incluso estaban sospechosamente en un "Huelga" algunos días antes y durante el 27F (excusa oficial, por su no represión los primeros días de la sublevación), tuvieron un papel primordial que explica que actuaron de manera coordinada para mover a la gente a desestabilizar el gobierno, a favor de intereses de fracciones del capital que tenían control político y económico sobre ellos.

Todo ello estuvo orientado a generar las condiciones idóneas para el intento de sedición, enfocado en la supresión de las medidas del FMI, el regreso a medidas proteccionistas y a una acumulación de carácter más nacional. Esos policías (usaban botas y armas de reglamento) estuvieron lanzando consignas contra CAP, los comerciantes y no era por un sentimiento anarco-socialista, era la intención de generar el caos que propicie la revuelta.

No sólo eso, son cientos los testigos que nos cuentan anécdotas del 27 y 28 de febrero, en la cual los policías directamente organizan los saqueos, lo cual pensamos, es una orden de algunos superiores. Vergel e Hernández (1990, p. 40) nos comenta:

En la calle atrás del Rosario, un policía usaba el megáfono de su patrulla para "organizar" los saqueos, decía: "[...] me hacen la cola doñitas, mujeres y viejitos primero" (Unos eran un tanto moralistas o anticonsumistas de la actualidad) otros decían: “ [...] eso no es necesidad doñita, no agarren de 10 latas de sardinas, agarren de 2, para que a otros les alcance [...]" [...] en Caracas se dejó hacer inicialmente, y después vino el pase de factura [...]. 
También el periodista Alfredo Tarre Muzi, con su seudónimo Sanín (1991), nos recuerda que:

La policía no solamente mostrábase impotente, sino que organizó algunos saqueos, de hecho estaban organizándolos para dar prioridad a mujeres y desvalidos, así como también prioridad al saqueo de alimentos, decían: "saqueen pero con orden", de poquito para que alcance para todos.

¿Era todo esto casualidad? No, a nuestro criterio hubo un componente conspirativo que intentó asirse del poder, mediante un plan de revuelta, sabotaje y desestabilización que aprovechó la valentía de un pueblo cansado de tanta opresión. Eso no quiere restarle el carácter espontáneo de muchas protestas, ni la falta de direccionalidad que se respiraba en el ambiente. Quienes conspiraron no planearon todo, sólo hicieron esfuerzos por provocar una situación que se les fue de las manos y que no pudieron canalizar hacia algo concreto (derrocar a CAP).

A esto, se le agregó la extraña fuga de 200 indigentes del albergue San Martín para incrementar los saqueos. O es que los policías tuvieron un par de días llenos de compresión y solidaridad o alguien les dirigió en el intento de sublevar al país.

Nada común ni corriente es la explicación que el economista José Gregorio Piña, actualmente trabajador del BCV, nos cuenta:

Me consta de primera mano, ya que nací y crecí en el Barrio El Manicomio (del que mi padre fue uno de sus fundadores y donde formó la primera célula del PCV en el Oeste de Caracas), que el saqueo fue organizado el primer día desde algunas instancias de Gobierno, que quienes saquearon ese primer día no lo hicieron por necesidad, en los días subsecuentes fue el hampa común que se dedicó a robar no había autoridad alguna. ${ }^{3}$

El 27F no fue un acto de mera casualidad, es poco menos que irresponsable ocultar centenares de testimonios que afirman las provocaciones y atisbos conspirativos en los sucesos.

\section{EN EL INTERIOR DE LA REPÚBLICA TAMBIÉN HUBO FUERTES PROTESTAS: EL CAFICARACAZO}

Nuestro amigo León Moraria lleva años tratando de comunicar una verdad silenciada con el pasar de los años. León estuvo

3 Testimonio del Economista José Gregorio Piña, enviado por Correo Electrónico. Testigo de excepción. 
dirigiendo a propia $\mathrm{VOz}$, junto con otros campesinos y proletarios rurales, una sublevación originada el 27F donde aparecen muchas informaciones útiles al análisis. León nos dice: ${ }^{4}$

[...] el fenómeno social conocido como el "caracazo", que no fue tan espontáneo y localista como suele decirse, por cuanto estuvo precedido por una gran movilización campesina de caficultores, y la toma del edificio del Ministerio de Agricultura y Cría en Barquisimeto, del Fondo Nacional del Café (Foncafé), en San Cristóbal [...] Es así, como, se produce la rebelión popular, el "caficaracazo".

No se niegan las rebeliones locales planificadas, ni alzamientos varios, ni otras acciones dirigidas a aprovechar políticamente la revuelta o incluso a generarla. Lo que si se evidencia que sólo el "shock" por las medidas y otras cuestiones técnicas no puede llevar la calle a perder la vida y a enfrentarse con Guardias Nacionales. Si hubo una depresión económica y factores estructurales, no se puede menospreciar acciones desde sectores del poder (gobierno, empresarios etc.) que trataron de encauzar a la protesta por otros derroteros.

\section{ESTALLA LA SUBLEVACIÓN CONTRA EL SISTEMA QUE LUMPENIZA A LA CLASE OBRERA}

Así las cosas, las capas medias aguantaron un poco de escasez, pero las zonas donde se concentran las barriadas más pobres reaccionaron abalanzadas a la calle, a buscar lo que le habían arrebatado, y como nos recuerda Alejandro Mendible, por la cobertura de la televisión a los saqueos, se incitaba a la gente a apropiarse de enseres de forma gratuita, ante la vista gorda de las autoridades. Cuando se empieza a restablecer el orden, sucede que lógicamente la televisión y radio dejan de informar y empiezan a regar los rumores de la tensa calma y claman por la paz.

En los barrios de Catia, 23 de enero, El Valle, La Vega, Caricuao, El Cementerio y en zonas muy pobres de La Guaira, estallaron los saqueos con mayor vigor. Buena parte de los trabajadores en situación precaria y el lumpen (muy numeroso) saliran a buscar alimentos y cualquier cosa que no podían comprar. No fue una

4 Este es un escrito enviado por León Moraria que suele publicarse los $27 \mathrm{~F}$ en prensa regional del Estado Lara, que queda a 5 horas de la capital. 
sublevación contra la propiedad, los propietarios o el poder político, fue una insurrección contra el sistema social que lumpenizaba a grandes capas de la clase obrera e impedía su acceso a la mínima supervivencia. Las escenas de gente con un cuarto de res en la espalda, radios, secadores y harinas recorrieron el mundo, y sellaron el fin de una época de una democracia tan represiva que no hizo falta dictadura.

\section{SE FRAGUÓ EL COMPLOT, SE INVITABA A SAQUEAR Y ROBAR. EL PLAN ERA DESESTABILIZAR}

Los pequeños y grandes locales empezaron a saquearse y el capital "víctima" del paquete trató de montarse en la ola y construir de facto su propia "Sociedad del 10 de Diciembre", una organización desordenada de lumpen dispuesto a morir en el vandalismo para que otros aprovecharsen el salto al poder. El capital afectado trató de aprovecharse del fuego al soplarle gasolina y ver como defenestraban al capital financiero y comercial que aplicaba políticas de ruina para la producción de bienes materiales. De esa forma, se urdió un complot con organismos policiales y mercenarios para dotar de algunas armas rudimentarias a quienes saqueaban, estimular los enfrentamientos con el ejército, abrir locales a la fuerza e invitar a su robo. ${ }^{5}$ El plan era desestabilizar y regresar al poder por la vía del ahogo económico.

La conspiración estaba en el aire, sin embargo, sus fuerzas eran débiles y las condiciones que citaba Lenin en Izquierdismo, enfermedad infantil en el comunismo referidas a que una crisis se da cuando las capas dominantes ya no pueden mandar como antes y los dominados no están dispuestos a aceptarlo, no se pudieron cristalizar. Así, su táctica tuvo que ser cobardemente escondida y replegada. En eso, el pueblo pobre salía a las calles con más intensidad de luchar por lo que le pertenece. Sin embargo, el 28 de abril CAP ratifica las medidas con la firma de la Carta de Intención con el FMI (lo que se trató de impedir con todas las fuerzas autonómicas desarrolladas a finales de febrero) y se muestra firme en su propósito de llevarlas a cabo.

5 Detalles de esto son relatados por Haleis Dávila, testigo de excepción y analista del $27 \mathrm{~F}$. 


\section{SUSPENSIÓN DE LAS GARANTÍAS CONSTITUCIONALES, COMIENZO DE LA SANGRIENTA REPRESIÓN}

El aciago 28 de febrero el ministro del Interior declaró la suspensión de las garantías constitucionales, el Plan Ávila y en las siguientes 36 horas las fuerzas armadas tomaron la ciudad, sembrando el pánico entre los manifestantes. Se sabe que mandaron a buscar el 28 de febrero a más de 10 mil efectivos del ejército, para que ellos aplacasen las protestas. La represión tuvo ribetes de insólita crueldad, que sólo se enmarcan en el intento de frenar una revuelta en proceso, no motines y saqueos disconexos.

A pesar que no había partidos políticos como guías, que no había dirección ni perspectivas serias de la toma del poder (salvo el capital "productivo" devenido en blanquista de nuevo cuño), las órdenes fueron exterminar todo brote de protesta de raíz. De esa forma, el ejército salió en las horas del toque de queda y empezó a asesinar a quien no oyera la voz de alto, incluso, se dispuso a disparar a los bloques y ranchos más humildes, dejando inválidas o matando a gente que estaba en su casa pacíficamente. Fue una especie de feroz retaliación, que en algunos casos dirigió la burguesía en aras de que no la saquearan, así, los patrones mandaban a ametrallar alrededores de sus negocios, llenando de balas a miles de inocentes.

La anarquía, las luchas autónomas a nada conducen. La falta de partido y preparación convirtió a las masas enardecidas en fáciles tiros al blanco para que la represión estatal diera muestras de todo su salvajismo. De hecho, no hubo gases lacrimógenos, ni ballenas, ni advertencias; policías y ejércitos usaron ametralladoras y todo tipo de arsenal bélico para asesinar a todos cuanto pudieron. Cada "toque de queda" era una reedición de la Noche de los cuchillos largos (operación nazi basada en asesinatos políticos y arrestos) en Venezuela. La orden que se cumplió a cabalidad era el asesinato en masa de cualquier transeúnte en cualquier actitud. O el allanamiento criminal a las casas en busca de "rastrear" la mercancía robada y devolverla a sus patrones quienes indignados pagaban a militares para mandar a recuperar lo suyo. Las redadas de recuperación de las mercancías saqueadas fue un acto de inmenso vejamen, donde el ejército expropió a miles de trabajadores 
objetos que compraron con miles de horas de trabajo. Entraban a la casa y se llevaban cualquier cosa que les diera la gana y se lo entregaban a la burguesía, que le pagaba recompensas y porcentajes de lo recuperado. Ejecutaron y desaparecieron a cientos que se negaron a esa humillación.

El ametrallar bloques enteros era la excusa, recibieron disparos desde los mismos. Y a pesar de que murieron oficiales en el combate, los disparos eran realizados con armas cortas, de bajo alcance y poco efectivos. Con esta "causa" se realizaban noche a noche jornadas de crímenes días después de la revuelta principal. Se detuvieron a cerca de 10 mil personas, se desaparecieron cerca de 100 y se torturaron a cientos, entre ellos, varios activistas universitarios, que poco tuvieron que ver con el desarrollo de la revuelta. Por supuesto, muchos de estos activistas intentaron de darle un cariz político a la revuelta y gallardamente trataron de canalizar la lucha hacia el desconocimiento del régimen. Lamentamos hondamente sus asesinatos.

La disolución del conflicto se hizo muy rápidamente. Las ejecuciones y torturas cobardes de los organismos represivos se hicieron extensivas. De hecho, soldados comentaban: "Aquí han matado soldados y cuando eso pasa arreciamos nuestro trabajo (matar) no es fuerte, porque ya uno está adoctrinado, acostumbrado y psicológicamente preparado" (PROGRAMA VENEZOLANO DE EDUCACIÓN-ACCIÓN EN DERECHOS HUMANO, 1989). La incapacidad y atomización de la protesta los hizo cómodas víctimas de la masacre. El espontaneísmo fue el cuchillo para su garganta. Las cifras indican cerca de 3 mil asesinatos, que para lo poco que duró el estallido, lo focalizado y estrictamente orientado a protestas de hambre, fue una cruenta demostración que cuando la burguesía pone orden, las transgresiones más abominables le quedan cortas.

\section{FRACASÓ EL MOVIMIENTISMO, AUTONOMISMO. ¿ QUÉ LECCIÓN NOS DEJÓ EL 27 DE FEBRERO?}

La masacre acaecida en los espacios de resistencia fue terrorífica y no condujo a ningún logro político. Más bien, dejó una ola romántica populista que dibuja a un pueblo heroico capaz de hacer lo que en ese momento no pudo, y creo yo, ni quería. La fiereza 
de la represión criolla sufrida por las miles de víctimas hace que la salvaje arremetida de la Guardia Blanca rusa, para disolver la protesta, que narra Eisenstein en la película La Huelga, sea vista como un juego de niños. Los mártires y luchadores que honestamente intentaron radicalizar u orientar políticamente los saqueos y las protestas hacia algo orgánico chocaron con el desarrollo anárquico que bajo peticiones abstractas y sin un partido que lo constituiría fracasó, y causó la muerte y lesiones de miles. De hecho, meses después CAP y sus bandidos recibirían más créditos del FMI y profundizarían sus políticas a todo vapor. Fue, de hecho, un impulso para el adocenamiento de la izquierda nacional, su democratización y electoralismo, caldo de cultivo para un oportunismo de leyenda.

Contrabandistas ideológicos, profesionales anticomunistas de izquierda, transfugas como Negri, Hardt, Holloway y los postmodernos "filosóficos" se trataron de aprovechar estos hechos para fundamentar imbecilidades como: cambiar el mundo sin tomar el poder, la inutilidad del sindicato, lo reaccionario del Partido y lo aburrido de la lucha de clases. Se equivocaron. El 27 de febrero es exactamente una prueba de lo contario. Es un acta que revela lo erróneo del camino.

Todo ello demuestra, a su vez, la necesidad de construir un partido de vanguardia que prepare y entrene a la clase obrera en el combate y permita dotarla de herramientas teórico prácticas para la toma del poder. El "Caracazo" iba a ser estéril, aún cuando CAP renunciase, debido a que no habían condiciones para asumir los cargos políticos vacantes, no había programa, partido, ni orientación alguna para tomar el poder y hacer algo diferente al capitalismo. La toma del poder y la construcción del socialismo revolucionario es un asunto científico que lleva años de investigación, práctica y lucha continua, que en el 27F no se podía concebir.

Incluso, un chavista tan apasionado como Antonio Aponte, quien firma sus escritos con la frase Chávez es el socialismo, dice: "Entender al 27 de febrero como un triunfo popular y un paradigma, es un error de apreciación histórica que aviva las ideas equivocadas (anarquismo y populismo)" (APONTE, 2008). El 27F fue un drama, un episodio de arrojo popular que terminó en tragedia. 
Beatificar este acto es una irresponsabilidad histórica y se constituye como factor de dispersión y confusión sobre las reales tareas que debe cumplir la clase obrera para trascender el sistema de explotación.

El 27F fue una sublevación intuitiva de gran valentía que no condujo sino a la muerte de miles y a un reflujo conservadurista en la lucha de clases. La misma se apoyó en una instigación manifiesta de las víctimas burguesas del paquete de medidas CAP-FMI. Si bien fue un ejemplo en América, una chispa de ilusión revolucionaria, su condición apartidaria y sin dirección muestra que el arte de la insurrección, las mezclas de la lucha legal e ilegal, la construcción del partido, la disciplina y la organización leninista rigurosa, son, aún, la única estrategia (comprobada) de transformación social profunda, que puede llevar a los oprimidos a la victoria sobre el capital. El movimientismo, el autonomismo y esa ristra de aventuras pequeño burguesas son vías expeditas al fracaso.

\section{REFERENCIAS}

APONTE, A. 4 y 27 de febrero dos fechas en contraste. 2008. Disponible en: <http://ungranodemaiz.blogspot.com/2008/03/4y-27-de-febrero-dos-fechas-en.html>. Acceso en: 14 mayo 2009.

\section{BARRIOS, S. Problemas urbanos y políticas urbanas} en países exportadores de petróleo: el caso del área metropolitana de Caracas. Caracas: Cendes, 1998.

CATLA, J. del L. Compilación el estallido de febrero. En P. Duno, P. Coup d'etat; en P. Arizmendi, A. Nace una esperanza. Caracas: Centauro, 1989.

CUEVA, A. El desarrollo capitalista en América Latina. México: Siglo XXI, 2007.

GONZÁLEZ, S. La ciudad venezolana, una interpretación de su espacio y sentido en la convivencia nacional. Caracas: Fundación para la Cultura Urbana, 2005.

ITURRIZA LÓPEZ, Reinaldo. 27F DE 1989: interpretaciones y estrategias. 27 FEB. 2009. Disponible en: <http://27f.blogspot. $\mathrm{com} />$. 
MARTÍNEZ, J. H. Causas e interpretaciones del caracazo. México: Universidad Nacional Autónoma de México, 2008. MARX, C. Obras scogidas. El Dieciocho brumario de Luis Bonaparte. Moscú: Progreso, 1915.

Grudrisses, elementos para la crítica a la economía política. Moscú: Progreso, 1858. Cap. II, tomo I de la sección del dinero.

OCHOA, A. E. Los golpes de febrero. Caracas: Centauro, 1989.

PROGRAMA VENEZOLANO DE EDUCACIÓN-ACCIÓN EN DERECHOS HUMANOS. Situación de derechos humanos en Venezuela. Caracas, 1989. (Informe octubre 1988-septiembre 1989).

RIVAS, R. El sacudón, el día que bajaron los cerros. Caracas, 1999. Disponible en: <http://www.amigospais-guaracabuya.org/ oagrv002.php>.

\section{SANÍN. Los muertos de la deuda o el final de la Venezuela} Saudita. Caracas: Centauro, 1991.

SARTELLI, E. La cajita infeliz. Argentina: RyR, 2004.

TOUSSAINT, É. Las finanzas contra los pueblos. La bolsa o la vida, [S.1.]: Comité para la Anulación de la Deuda del Tercer Mundo, 2004. Cap. 16, Ruanda: los acreedores del genocidio. Disponible en: <http://www.cadtm.org>. Acceso en: 16 mar. 2009.

VERGEL, S.; HERNÁNDEZ, W. El lunes sangriento de la cuaresma venezolana. 1990. Tesis (Grado de Comunicadores Sociales) - Universidad Central de Venezuela, Caracas, 1990.

VIVAS, S. J. Aquella mañana de un 27 de febrero. Disponible en: <http://www.aporrea.org/actualidad/a12248.html>. Acceso en: 24 feb. 2005.

ZAMBRANO, J. R. Causas de la Insurrección del 27-28 de febrero y los primeros días de marzo. Revista Cantaclaro, Venezuela, 1989. Suplemento del CC del PCV. 